\title{
Testimonios
}

\section{Recordando mi travesía hacia el norte y sus múltiples trabas del camino}

\author{
Por Víctor Diaz*
}

Honduras, cuatro de enero de 2005. Ese día salí rumbo a Estados Unidos con un solo objetivo: estar dos años, pagar los costos del viaje y hacer casa a la familia. Eran las cinco de la mañana. Mi tío Agustín, en el carro de Andrés, su hijo, nos condujo hasta el lugar llamado Baracoa en el departamento de Cortés. Salimos cuatro, todos con parentesco familiar. Después tomamos el autobús que conduce a Puerto Cortés y luego el autobús que conduce a la frontera de Corinto. En la frontera, en una garita de migración pagamos la salida, cincuenta quetzales. Tomamos un microbús que conducía a Puerto Barrios, seguimos y nos bajamos en el desvío que conduce hacia Aguas Dulces para tomar el autobús que viene de Guatemala hacia la ciudad de Santa Elena, una vez ahí compramos algo de comer. Puedo decir que en estas circunstancias uno está nervioso y no tiene muchas ganas de comer. Lo único que desea es que pase el bus; uno tiene miedo de que venga un policía, pida papeles y le saque unos cuantos quetzales más.

A la mitad del camino hay un retén militar, nos bajan a todos y revisan las maletas. La razón que dan es para detectar armas o drogas. Continuamos el camino llegando a Santa Elena a eso de las siete y treinta de la noche. Buscamos algo de cenar, lo más conocido y barato fue pollo. Pues eso compramos y comimos. Dormimos en un hotel en donde los cuartos eran divididos por playwood; un cuarto para cuatro personas. La cosa es ahorrar.

Guatemala, cinco de enero. Salimos a las siete de la mañana para El Naranjo. Ese lugar está a poco más de una hora de Santa Elena. Ahí hay dos opciones de viaje para la frontera con México: por agua o por tierra. Nuestra opción fue por tierra a un lugar llamado La Paz, perteneciente a Guatemala. Todavía era la una de la tarde cuando llegamos. Descansamos un poco antes de cruzar la frontera pues ahí nos

* Promotor social del Equipo de Reflexión, Investigación y Comunicación (ERIC), El Progreso, Honduras. 
decían que los militares estaban vigilando el lugar. Creo que alguien quería hacer negocio con nosotros haciéndose pasar por guía, pero no le funcionó el truco ya que uno de los compañeros, Víctor Manuel Sánchez, conocía el camino. A eso de las cuatro de la tarde salimos rumbo a Cenote, una aldea perteneciente al Estado de Tabasco, México. Ahí un amigo de Víctor, don Lenín, nos daría alojamiento. Pagamos por pasar la noche en una casa abierta, compramos algo de comer e investigamos cómo estaba la salida del autobús. Sólo es uno. Y un día sale para Tenosique y otro día para Balancán. Por suerte el viaje era hacia nuestro destino, así que sólo teníamos que esperar a que amaneciera.

México, seis de enero. Salimos a las seis de la mañana de Cenote a Balancán. Apenas llegamos al desvío que conduce a la playa nos cayó la Policía. Nos agarraron, excepto a mi primo Andrés, quien andaba haciendo sus necesidades. Él siguió el camino.

Los tres, Víctor Sánchez, Agustín Alvarenga (primo) y yo le ofrecimos algo de dinero a la Policía, pero no fue posible que nos soltaran porque ya estábamos en la Delegación Municipal. Éramos los primeros del año que arrestaban. Nos tomaron una entrevista preguntando cómo estaba la situación en nuestro país. Pasamos el primer día y el segundo día, y nos fueron tomando confianza, luego nos sacaron al patio. Víctor Sánchez echó una "ojeada” por el edificio y dijo que era fácil que nos escapáramos. Así lo hicimos. A la mañana del siguiente día subimos al segundo piso y nos escapamos. El problema fue que ya había personas en el parque que está frente al edificio municipal. Nos vieron y nos denunciaron. Empezaron a buscarnos y nos detectaron, corrimos pero fue imposible huir. Nos capturaron. A Víctor Sánchez lo golpearon aduciendo que él era el promotor de la fuga. En realidad a mí me habían tomado un poco de aprecio porque una noche antes de escapar, cuando nos sacaron al patio les dije que escribía poemas y les gustó. Les leí algunos. Incluso se identificaron con algunos de los escritos.

En la tarde del día siguiente nos trasladaron a Tenosique, donde permanecimos otra cantidad de días. Después nos trasladaron a Talismán, frontera guatemalteca. Al siguiente día nos trasladaron a la frontera hondureña de Aguas Calientes y tomamos el autobús para San Pedro Sula. No teníamos problema con los pasajes pues yo andaba suficiente dinero. Incluso recuerdo que presté trescientos lempiras a alguien que no conocía que, desde luego, sabía que no me pagaría. Ya estábamos a veinte de enero, vísperas del veintiuno de enero, fecha en la que cumplía el quinto aniversario de pareja con mi compañera Iris.

Mi tío Agustín nos fue a encontrar a San Pedro Sula, llegamos a las once de la noche y amanecimos el veintidós de enero de nuevo en Urraco.

El veintitrés de enero, muy de mañanita, salimos nuevamente haciendo el mismo recorrido con la diferencia que acordamos decir que éramos mojados y lo haríamos desde ya, burlando la aduana de Honduras y de Guatemala. Dijimos que íbamos mojados y no pagaríamos ni salida ni entrada. Ese día llegamos hasta El Naranjo, dormimos en un corredor y antes de que amaneciera tomamos el carro que nos conducía por segunda vez a La Paz, frontera guatemalteca y mexicana. Ese día dormimos de nuevo donde don Lenín. En el grupo iban algunas mujeres y, 
por cierto, un hijo de don Lenín quería tener relaciones sexuales con una de las muchachas.

Veinticuatro de enero. Salimos nuevamente antes del amanecer. Llegamos a Balancán donde tomamos el autobús al desvío de Playa. Rodeamos la garita de migración y nos tiramos por el terreno que pertenece a una base militar. En ese momento venían hacia nosotros dos hombres a caballo. Aceleramos el paso, nos pasamos al otro lado del alambre y seguimos caminando. Cuando estábamos por salir a tomar el autobús que nos conduciría a Villa Hermosa nos cayó un carrito turismo con tres agentes de migración que nos dijeron: "Alto. Somos de migración". Salimos corriendo, saltamos un alambre en el que dejé pedazos de camisa y pantalón. Más adelante me tiré cansado y solo. De pronto escuché que alguien picaba algo con un machete, levanté la cabeza y vi que eran dos jóvenes. Traté de esconderme pero la maleza era pequeña. Uno de ellos me vio y le dijo al otro: "Mirá lo que tenemos aquí". Se dirigió a mí y me dijo: "Cuidado salís corriendo porque por ahí se nos fue uno que parecía bala”. Era un salvadoreño que encontramos en el camino. Me pidieron quinientos pesos pero sólo les ajusté doscientos. Les prometí ajustarles con ropa pero dijeron que lo que les interesaba era el dinero. Tomaron los doscientos y me dejaron ir. Me recomendaron que tomara bus en una hacienda que estaba cerca de ahí.

Cuando llegué a la hacienda encontré al salvadoreño terminando de almorzar. Me dieron comida y después me cobraron veinticinco pesos. Yo pensaba que era de caridad. Luego nos prometieron que por cien pesos cada uno nos llevarían a la parada del bus. Así fue, cuando paró el automóvil nos hizo señas para que saliéramos de prisa. Cuando nos sentamos dijo un joven: "Por estos es que nos jode la migra a nosotros". En ese trayecto, en un reten militar subió un soldado que le sacó doscientos pesos al salvadoreño, luego se dirigió hacia mí y me pidió cien pesos. Le dije que sólo tenía cincuenta pero que podía conseguir lo demás con mi amigo. Me dijo: "No te muevas, sólo ponlos aquí despacito que no vean los que están abajo”. Después de eso, todo bien. Llegué a Villa Hermosa casi a las siete de la noche y me encontré con Andrés Alvarenga y con Víctor Sánchez. Ellos ya habían avisado a Honduras que la migra me había "agarrado". Sentimos alegría al encontrarnos, creo que más yo porque ellos ya conocían el camino. Inmediatamente buscamos la casa de los Jesuitas en cárdenas. Ahí estaba la comunidad de Florentino, un amigo de Jorge Atilano a quien conocí en Huatusco, Veracruz, en la ordenación de Jorge. Ahí permanecimos tres días. Los miembros de la comunidad, en medio de sus ocupaciones, dedicaron tiempo para retirar los fondos que nos enviaron nuestros familiares de los Estados Unidos. Luego, con un "costal de nervios" salimos a tomar el autobús que nos trasladaría hacia más adelante.

Ese día pasamos por el desvío de Aguas Dulces, donde encontramos otro retén. Siempre que uno ve un retén militar se preocupa, pero por suerte esta vez no subieron a revisar el autobús. Pasamos por Coatzacoalcos y llegamos a Minatitlán, donde tomamos el camino para rodear las garitas de migración. Llegamos a un pueblo antes de San Andrés por recomendaciones de los Jesuitas de Cárdenas.

Un jesuita, cuyo nombre no anoté, nos desvió de camino. Dijo que por el camino que llevábamos era peligroso porque la montaña que estaba de frente era 
Lacandona y que era una zona no recomendable porque hay presencia militar. Dijo que regresáramos con cuidado porque aunque ese no era camino de migrantes teníamos que tener precaución de la Policía. Nos dio doscientos pesos y salimos nuevamente en camino. Una vez en la carretera internacional tomamos un autobús que nos conduciría a San Andrés. Ahí fuimos a la catedral, había misa y cuando terminó buscamos al Padre Jeremías para pedirle hospedaje por esa noche. Desacomodaron a unos novicios y nos dieron su cuarto; una cama para tres. Nos invitaron a cenar y en la mañana nos ofrecieron desayuno y "jalón" hasta cerca de Veracruz. Nos desearon suerte.

A eso de las once de la mañana llegamos a Veracruz. Buscamos la manera de comunicarnos con Giovanni en Huatusco, esposo de Teresa, prima de Jorge Atilano. Él contrató un taxista que nos fue a traer al anochecer. Nos encontramos en la Catedral; durante el tiempo de espera escuchamos dos eucaristías. Llegamos a las ocho de la noche a Huatusco, ahí nos esperaba una buena cena de manos de Teresa, la esposa de Giovanni. Al día siguiente salimos a La Alameda, un parque. No dijeron que debíamos de tener cuidado porque enfrente de la casa vive un miembro de la Policía que aunque es buen vecino, no hay que confiarse. Ahí permanecimos por quince días, en ese tiempo ayudé a Giovanni en la venta de tortillas que distribuía en moto en los ranchos aledaños. Fui chofer en ese pueblo y no era necesario tener licencia de conducir.

El día quince de febrero de 2005 se contrató un taxista que nos condujo hasta Orizaba. Ya llevábamos los boletos comprados; cada uno costó 750 pesos. Después de un buen rato de espera llegó el autobús que nos conduciría al Distrito Federal. Después de tres horas de camino, llegamos. Salimos a la Estación del Metro que está al lado. Para nuestra sorpresa, la Policía nos esperaba. Sabían que íbamos tres mojados, tenían todas las descripciones. Nos detuvieron, nos subieron al segundo piso y nos preguntaron: “Dónde está el otro?”. Les respondimos que sólo éramos dos. "No", dijeron, "falta el trigueñito colocho".

Bueno, comenzaron las negociaciones. Querían cuatrocientos pesos por cada uno. Les dijimos que ya estábamos desplumados, que nos consideraran un poco. Nos dijeron: “Qué prefieren, 'mocharnos' con esa plata o regresar a la frontera? Miren que ya están bien arriba”. Finalmente sólo pagamos doscientos cincuenta cada uno, quinientos en total. Bajamos a tomar el metro y vimos a Andrés con gorra y sin la chaqueta.

Salimos para la Basílica de Guadalupe. Puestos ahí llamaríamos a Perla y Chabela quienes vendrían por nosotros y nos llevarían a Cuautepec, barrio alto de la Ciudad de México popularmente conocido como La Pastora en el Cerro del Chiquigüite. Ellas ya sabían que habíamos salido de Huatusco. Como sentimos que se nos había hecho tarde no la llamamos y ella se quedó esperando para venir por nosotros. Víctor Sánchez dijo: "aquí peguémonos a estos peregrinos para estar seguros". Pero ellos se sintieron amenazados y lo hicieron saber a la Policía, que vino a preguntar de dónde veníamos. Yo dije que de Huatusco a cumplir una promesa hecha a nuestra madre de Guadalupe. Entonces nos pidieron que no estuviéramos cerca de los peregrinos porque se sentían inseguros con nosotros cerca de ellos. Buscamos dónde dormir en uno de los puestos que venden durante el día. 
Encontramos un cartoncito y a dormir. Pero la ciudad es muy helada y a cada rato nos despertaba el frío. La mañana siguiente teníamos que hablarle a Perla pero no teníamos monedas ni cómo conseguirlas. Si lo que uno más tiene es miedo.

Entramos a la misa. Me le pegué a un Padre y sin saber siquiera su nombre le digo que necesito hacer una llamada. "Aquí tenemos teléfono pero sólo sacerdotes entramos", me dijo. Luego me dijo: "Seguidme". Me fui tras él y entramos. No nos paró el guardia. Me dijo: "Eres una persona con mucha suerte”. Me marcó el número y me dijo: "Cuando termines de hablar saldrás por esta otra puerta". Nos pusimos de acuerdo con Perla sobre dónde nos encontraría. Justo frente al monumento de Juan Pablo segundo. Cuando salí me preguntó el guardia: "Padre, ¿usted es de los que entraron a las siete?” Sí, le dije. Y me dejó pasar. ¡Ja,ja,ja!

Luego no tardaron en llegar por nosotros. Nos encontramos con Perla y salimos para su casa. Ya puestos en ella nos dieron desayuno, un lugar donde descansar y luego, el contacto con el coyote. Ese mismo día a las cuatro de la tarde salimos con ellas y nos entregaron al responsable de llevarnos. Como a las seis de la tarde estábamos en Querétaro en manos del coyote, don Exequiel, su verdadero nombre Daniel. Nos condujo a su rancho en Los Pocitos, Querétaro, una comunidad de donde saldríamos tres días después.

Así fue, salimos de Querétaro a las ocho de la noche y llegamos a la frontera a la ciudad de Laredo a las ocho de la mañana. Ahí pasamos el día y realizamos las compras necesarias para el camino: comida enlatada, agua, pan, dulces, bolsas grandes para la noche, etc. Como a eso de las tres de la tarde salimos rumbo a San Jesús, lugar en la mera frontera. Pasamos un retén militar, subieron al bus pero no pasó nada. Algo le preguntaron a Andrés pero no supe qué. Y pasamos. Minutos después paró el bus y todos bajamos. Ahí ya éramos quince personas: once mexicanos, tres centroamericanos y el guía o coyote, don Exequiel. Caminamos cerca del Río Bravo. Descansamos. A las cinco de la tarde cruzamos con el agua a la cintura y ya estábamos en tierra gringa. Seguimos caminando y cayó la noche. Como a las ocho entramos en un cruce de camino y al chocar con un pequeño grupo cada quien salió enrumbado pensando que era la migra. Después regresamos al camino. "Parece que eran caminantes igual que nosotros", dijo el guía. A todo esto los coyotes aullaban y claro, yo algo de miedo sentía y seguro que no era el único. Así pasamos las horas. Como a la una de la madrugada nos tocó dormir en el desierto. Cuando puse las nalgas en el suelo, jay qué helado estaba! Hasta en los huesos sentí el frío, pero el cansancio pudo más. Al comienzo la bolsa que llevaba estaba toda helada pero luego se fue medio calentando.

En la mañana nos levantamos a seguir caminando todos duros de la 'helazón'. Sólo caminamos hasta las ocho y nos quedamos en un matorral grande esperando la tarde para continuar el viaje. Salimos ese día a las cuatro de la tarde. Ya el agua era escaza y llenábamos de las pilas que tenían para el ganado. Era agua entre dulce y salada. Recuerdo esa noche que la sed era insoportable. Llegamos a un arroyo, nos agachamos y el agua al pasar por la garganta se sentía pura sal, nos quedó ardiendo. Esa noche pasamos por lugares que, según nos dijeron, eran refinerías de petróleo. Como a eso de las dos de la madrugada nos tocó cruzar la calle de asfalto. El cruce se hace cuando no hay ningún vehículo porque ese puesto es vigilado por migración. Pasamos en tropel. Luego pasamos por otra refinería. Adelante vimos 
una luz que a nuestros ojos parecía sospechosa y salimos agachados y corriendo uno tras otro. El guía nos contó y dijo: "falta uno". Era Víctor Sánchez, quien ya traía los pies pelados del camino. Como nadie se puede regresar lo dejamos perdido.

Saltamos algunos cercos, vimos manadas de venados y unos animales grandes como conejos con grandes orejas; dijeron que eran liebres. Llegamos a orillas de un lugar llamado El Espino. Ahí esperamos la noche. El guía realizó algunas llamadas y nos dijo: "a las siete salimos para Dallas Texas". Cuando llegó el carro nos tiraron al piso, unos sobre otros. Cuando llegamos a San Antonio Texas nos compraron una hamburguesa para cada uno, esa fue la cena. A las diez de la noche llegamos a la casa, nos dimos un baño y nos cambiamos la ropa. Llamamos a nuestros familiares para que depositaran el dinero y los guías nos enviaran para nuestro lugar de destino después de recibirlo.

Salimos al punto de buses que conducen a diferentes ciudades de los Estados. En el punto nos encontramos con Víctor Sánchez. Según nos contó, lo encontraron unos cazadores de venados y se lo llevaron a Dallas. Ahí nos separamos. Ellos se fueron para Miami y yo para Virginia. Llegué veintisiete horas después. Me esperaba mi hermano Santos con su amigo José. Mi primera cena en Fairfax fue en un restaurante cuyos dueños son salvadoreños. Después nos fuimos a casa en la calle Layton Hall. Era el veintisiete de febrero de 2005. 